\title{
An Examination and Analysis of Municipal Scientific and Applied University Students Entrepreneurial Attitude
}

\author{
Peyman Pournasr Khakbaz \\ Islamic Azad University, Science and Research Branch, Tehran, Iran \\ p.pournasr@yahoo.com
}

\begin{abstract}
At the time, entrepreneurship training has evolved into of the main and expansive academic activities, and developing academic students' abilities owes to expanding and upbringing entrepreneurship capabilities. Accordingly, examining entrepreneurial attitude of university students which itself is the most significant alternatives of launching new businesses and knowledge-based, can be helpful in purposeful entrepreneurship trainings and lead them to proper trend. In this study, entrepreneurial attitude of Municipal Scientific and Applied University students was examined at individual level regarding major indices such as entrepreneurial attitude, proactiveness, risk-taking, creativity and innovation, autonomy, and competitive aggressiveness, and it was demonstrated that the students were at suitable level considering entrepreneurial attitude. In addition, since many of them were interested in attending entrepreneurship courses, it is possible to actualize the potential attitude and tendency by including entrepreneurship-training courses at different faculties and lead them to establish businesses in a purposeful way.
\end{abstract}

Key words: Entrepreneurial attitude, risk-taking, success-centeredness, innovation, autonomy, competitive aggressiveness

\section{Introduction}

$1^{\text {st }}$ century can be called the century of entrepreneurs. In different countries of the world, at each second, a new business enters the market. Today generation of the entrepreneurs has established an incredible number of new and prosperous businesses with providing high quality products. The entrepreneur takes a chance for innovation, producing a new product and making and evolution. He makes this by leading economic sources from low efficiency businesses to highly efficient activities (Autio et al, 2001). There is a variety of reasons for launching a new economic activity. A study implies the fact that seven main factors sparking on the activities are need for improvement, need for autonomy, need for promotion and personal status, wealth making, valuing wealth, lower tax and indirect earnings, and following role models (Chen and Lai, 2010). Most studies regarding entrepreneurship have been focused on entrepreneur and always the question posed that why do certain individuals establish companies but the others do not? Because they own certain innate qualities. The focus in any study seeks to detect distinguishing factors among entrepreneurs and non-entrepreneurs. The need for success, internal control, risk-taking, values and observing them are among other qualities considered (Fazio, 1990). However, researchers have consensus that there are many reasons for establishing a company, entrepreneurs motivations usually depend on personality and environmental factors (Gibson et al., 2011). Nevertheless, many researchers have discussed the characteristics of entrepreneurs; yet, competencies required for launching a new business are just examined in one dimension (Erich et al, 2009).

In Iran and in particular among the students, entrepreneurship is not promoted so much. In addition, unfortunately, graduates are searching for being employed firstly by governmental system and then by important companies. Therefore, their employment is of the main concern of high education system. As a result, it seems the removing the problem owes to developing and expanding entrepreneurship capabilities in the students, which in turn requires knowing their capabilities and the extent of tendencies toward entrepreneurship. At the time, training entrepreneurship is among the main academic activities. In fact, the main objective of this is to train individuals with self-confidence and aware of chances and in general the ones with strong motivation to take opportunities and launch new businesses and the ones who can turn new ideas into profitable and commercial realities in form of goods and services the society needs. On the other hand, one of the main and widely accepted presumptions is that the individuals' entrepreneurial tendencies can affect their activity levels in different fields. Most entrepreneurial attitudes are learnable and based on family training, social environment and workplace. Therefore, they 
can be evolved by training and interference; among which university and academic environment play great role. Results from the studies show that some university factors like management style, teachers qualities, financial-official system, Staff performance, students characteristics, and course content have correlation with entrepreneurial attitudes of the students (at five aspects of entrepreneurial attitude, proactiveness, risk-taking, creativity and innovation, autonomy, and competitive aggressiveness) and factors like accessing instructional equipments and educational spaces do not correlate entrepreneurial attitudes of the students. In addition, four factors of management style, financial-official system, and Staff performance respectively are considered as the most notorious challenges of entrepreneurial attitudes of the students (Harris and Gibson, 2008). The main question of this study is that which components encourage the individuals to take high risks for launching an activity or a business. On the other hand, what are the main motivations and attitudes of the individuals to do risky activities and at what extent are tendencies and motivations of different individuals?

\section{Entrepreneurial Attitude in Entrepreneurship Theories Evolution Course}

Florin et al (2007) present three main classes of research regarding entrepreneurship field.

- First class regards that entrepreneurs activities and results of their activities are inherent. In this view, the focus is on large-scale economic activity and performance results and savings.

- The second implies mostly social and psychological aspects of entrepreneur, background, objectives, values and motivations of the human and focuses on entrepreneur as an individual.

- The third emphasizes on estate of entrepreneur's affairs and that how he accomplishes his objectives (not considering environmental and personal factors for overcoming sources and achieving the objectives) and on management aspects. The class is related to management and behavior of the entrepreneur.

Early entrepreneurship studies were individual-oriented and then they tended to company. Based on Shumpiter's views, finally entrepreneurship was turned into dominant aspect of the organization so that further sources were allocated to innovation (Kundu and Rani, 2008). Recently, corporation concept of entrepreneurship is considered as strategic growth tool of the big organizations. This is very important for the organizations seeking entrepreneurial activities advantages (Michael and Shanon, 2008). As a result, strategic essence of entrepreneurship leads to develop entrepreneurship-specific flows. Entrepreneurial attitude is related to each individual in an organization. Many researchers including Naffziger et al (1994) have barrowed ideas and concepts of entrepreneurial attitude from strategic management literature (Gibson et al., 2010). Entrepreneurial attitude based on Das and Lumpkin is determined to processes, methods and activities of decision making for entering and launching a new business activity. Phrase "entrepreneurial attitude" implies a set of personal characteristics, values and attitudes and strong attitudes related to motivation of warrantors in entrepreneurial activities (Shariff and Saud, 2009). Olson and Bosserman (1984) - as a pioneer in strategic management - have presented three planning, comparative and entrepreneurial styles for management of an agency.

Accordingly, entrepreneurship style means an active attempt ad search for new opportunities and a noticeable jump facing unreliable situations. Fredrickson has presented aspects like holisticcenteredness, progressiveness, rationality, risk-taking, courage and brief thought as an agency's entrepreneurship aspects. Miller believes that entrepreneurial agency is involved in product-market creativity, risk-taking for investments and creativity in progression (Stormer et al., 1999). Harris and Gibson (2008) added the concept of competitive aggressiveness and autonomy to other theoreticians' concepts as leading aspects entrepreneurship and completed their views. They put it that agencies interested in being involved in entrepreneurship have to be committed to entrepreneurial attitude. Entrepreneurial attitude indicates strategic activities conducted for detecting and launching risky investments at agency level. In addition, it provides a mental and attitudinal framework for entrepreneur reflected in sustainable processes and culture of the agency. They relate entrepreneurial attitude concepts inside the agency and main entrepreneurial processes of the agency. In addition, they determine entrepreneurial attitude by five main factors including proactiveness, risk-taking, creativity and innovation, autonomy, and competitive aggressiveness. In Table 1, entrepreneurial attitude aspects of the agency from Harris and Gibson's Point of view are provided.

Entrepreneurial Attitude theory is based on the presumption that entrepreneurial companies are different from other companies. Early studies of Entrepreneurial Attitude imply that entrepreneurial companies tend to take higher risks than other companies do. In addition, the companies are actively 
seeking for new business opportunities (Harris and Gibson, 2008). Results indicate that there is a relationship between entrepreneurship indices including progression, aggressive competition, risktaking, innovation and success-centeredness and small businesses performance (Rosenberg and Hovland, 1960). In addition, tendency toward corporation Entrepreneurship affects business performance and results in an enhancement of employees and customers satisfaction as well as its financial performance improvement (Robinson et al., 1991). Miller considers risk-taking and being active as the characteristic of entrepreneur companies in outer environment rather than acting impulsive to environmental stimulations (Mentoor and Friedrich, 2007). Results from Peterman and Kennedy's study show that those small and medium industries owners are in good conditions at growth aspects including successcenteredness, ambition, autonomy and entrepreneurial attitude aspects including progression, aggressive competition, risk-taking, innovation and success-centeredness.

Table 1: Entrepreneurial Attitude Aspects of the Agency from Harris and Gibson's Point of view

\begin{tabular}{|c|c|}
\hline Aspects & Definitions \\
\hline Autonomy & $\begin{array}{l}\text { Independent activities of individuals or teams to create and fulfill a business or } \\
\text { operate a prospective }\end{array}$ \\
\hline Innovativeness & $\begin{array}{l}\text { A tendency of ward presenting novice ideas based on experiment and creative } \\
\text { processes to expand new services and products and even new processes }\end{array}$ \\
\hline Proactiveness & $\begin{array}{l}\text { nal view applied by market leader to detect and take the opportunities } \\
\text { ture demand }\end{array}$ \\
\hline $\begin{array}{l}\text { Competitive } \\
\text { aggressiveness }\end{array}$ & $\begin{array}{l}\text { New attempt to overtake industrial rivals happening in competitive market through } \\
\text { competitive aggressiveness to improve agency status and/or overcome the threats }\end{array}$ \\
\hline Risk-taking & $\begin{array}{l}\text { Decision making and fulfilling the activities without relying on certain kind of } \\
\text { knowledge and awareness of probable results }\end{array}$ \\
\hline
\end{tabular}

Source: Harris and Gibson, 2008

Table 2: Major studies conducted cross-country regarding entrepreneurial attitude at company level

\begin{tabular}{|c|c|c|}
\hline Aspect & Study area & Researcher \\
\hline Risk-taking & $\begin{array}{l}\text { Entrepreneur companies generally take higher risk } \\
\text { strategies }\end{array}$ & Liñán et al., 2010 \\
\hline Risk-taking. Flexibility & $\begin{array}{l}\text { Entrepreneur companies are better risk-takers than } \\
\text { the other companies }\end{array}$ & McCline at al., 2000 \\
\hline Risk-taking, innovation & $\begin{array}{l}\text { Entrepreneur companies have higher product- } \\
\text { innovation levels than the conservative ones }\end{array}$ & Ramsdal, 2008 \\
\hline $\begin{array}{l}\text { Risk-taking, innovation, } \\
\text { proactiveness }\end{array}$ & $\begin{array}{l}\text { Entrepreneurship components affect the type of a } \\
\text { company }\end{array}$ & Schwarz et al., 2009 \\
\hline Analysis, innovation & $\begin{array}{l}\text { There is a better relationship between } \\
\text { entrepreneurial attitude and environment in } \\
\text { successful companies }\end{array}$ & Vecchio et al., 2003 \\
\hline $\begin{array}{l}\text { Innovation, risk-taking, } \\
\text { proactiveness }\end{array}$ & $\begin{array}{l}\text { Performance of the company depends on } \\
\text { adaptability of entrepreneurial attitude, structure } \\
\text { and environment }\end{array}$ & $\begin{array}{l}\text { Mentoor and Friedrich, } \\
2007\end{array}$ \\
\hline $\begin{array}{l}\text { Risk-taking, proactivity } \\
\text { and innovation }\end{array}$ & $\begin{array}{l}\text { The relationship between entrepreneurial attitude } \\
\text { and company performance is modified by a variety } \\
\text { of internal and external and strategic variables }\end{array}$ & McCline et al., 2000 \\
\hline $\begin{array}{l}\text { Risk-taking, } \\
\text { proactiveness, } \\
\text { innovation }\end{array}$ & $\begin{array}{l}\text { Risk-taking new businesses have higher levels of } \\
\text { entrepreneurial attitude in different environments }\end{array}$ & Florin et al., 2007 \\
\hline $\begin{array}{l}\text { Risk-taking, } \\
\text { proactiveness, } \\
\text { innovation }\end{array}$ & $\begin{array}{l}\text { Direct relationship between entrepreneurial } \\
\text { attitude and performance will increase in time }\end{array}$ & Gibson et al., 2010 \\
\hline $\begin{array}{l}\text { Risk-taking, innovation, } \\
\text { proactiveness }\end{array}$ & $\begin{array}{l}\text { Hostility modifies the relationship between } \\
\text { international corporative entrepreneurship and } \\
\text { performance }\end{array}$ & Chen and Lai, 2010 \\
\hline
\end{tabular}

Source: Henderson and Robertson (2000)

On the other hand, tendency of growth and entrepreneurial attitude has positive effect in small and medium businesses (Peterman and Kennedy, 2003). Despite disagreement on individual criteria of 
determining entrepreneurial attitude, most emphasis is on Covin and Slevin's measures that have great focus on three elements of risk-taking, innovation and proactiveness. However, the measures alternatively are not clear, but in fact, they include a psychological evaluation of the individuals' entrepreneurial attitude (Covin and Slevin, 2002). Nevertheless, entrepreneurial attitude in entrepreneurship literature has been addressed in two personal and company levels. Tables 2 and 3 are presented the studies in two distinct fields. Generally, studies conducted on entrepreneurial attitude either at personal or company level, each implies some factors as entrepreneurial attitude and tendencies of independent and company entrepreneurs for taking risk, however, some of them are in common in most studies which are:

- Proactiveness attitude: includes average planning to use future employment opportunities, the extent of seeking new chances in the field of study and enhancing educational competency.

- Innovation attitude: includes average tendency of invention, innovation and zeal for gaining business competency.

- Autonomy attitude: includes average tendency of presenting new ideas in field of study, cooperation in a creative environment, employing new ideas in workplace and discovering and representing new ideas in workplace.

- Risk-taking attitude: includes average extent of taking progressive changes, taking risk comparing to others and belief and tendency of taking progressive chances.

- Competitive aggressiveness attitude: includes average tendency amount of competing the others, overtaking rivals based on competency and extent of presence in highly competitive environments.

Theoretical Framework and Research Components: Considering the matter that this study examines entrepreneurial attitude of Municipal Scientific and Applied University students at individual level and literature review, five major indices of entrepreneurial attitude, proactiveness, risk-taking, creativity and innovation, autonomy, and competitive aggressiveness extracting from Harris and Gibson's entrepreneurial attitude aspects are studied. Accordingly, research hypotheses are:

Main Hypothesis: municipal Scientific and Applied University students are in appropriate status regarding entrepreneurship attitude.

\section{Secondary Hypotheses:}

Municipal Scientific and Applied University Students are in appropriate status regarding autonomy.

Municipal Scientific and Applied University Students are in appropriate status regarding creativity and innovation.

Municipal Scientific and Applied University Students are in appropriate status regarding proactiveness.

Municipal Scientific and Applied University Students are in appropriate status regarding competitive aggressiveness.

Municipal Scientific and Applied University Students are in appropriate status regarding risk-taking.

\section{Methodology}

The study is mainly aimed at examining the extent of entrepreneurial attitude of Municipal Scientific and Applied University students. Therefore, present study is an applied research. Also, based on data collection procedure (field and library methods), it can be considered as descriptive-survey study. Statistical community of the study comprises 642 Municipal Scientific and Applied University students at all grades. To gather subject literature and background review of entrepreneurial attitude, library method and questioner were also applied as essential tools selected for collecting field data (statistical community research components examination). To distribute the questioners among respondents and data collection, simple class sampling and Kukran calculation formula as the basic measure for determining volume of the sample were used. In addition, according to Kukran formula, 254 subjects were selected as sample volume.

$$
n=\frac{N z^{2} \alpha / 2 p(1-p)}{(N-1) \xi^{2}+z^{2} \alpha / 2 p(1-p)}=\frac{(5642)\left(1.96^{2}\right)(0.5)(0.5)}{\left((5642-1)\left(0.06^{2}\right)\right)+\left(\left(1.96^{2}\right)(0.5)(0.5)\right)}=254
$$

Then, the sample was divided into 8 classes based on faculties and each faculty's students were tested by random sampling resulting in 254 questioners gathered as follow: 


\begin{tabular}{lllllllll}
\hline Faculty & Agriculture & $\begin{array}{l}\text { Technical \& } \\
\text { engineering }\end{array}$ & Humanities & Art & Medicine & Dentistry & Nursing & $\begin{array}{l}\text { Basic } \\
\text { sciences }\end{array}$ \\
\hline Frequency & 23 & 44 & 73 & 27 & 27 & 24 & 7 & 29 \\
\hline
\end{tabular}

The questioner was designed and structured using closed multiple-choice questions regarding entrepreneurial attitude of students and components of autonomy, innovation, risk-taking, competitive aggressiveness, and proactiveness extent. For the sake of validity, some expert views were used and the questioner was confirmed by them and for reliability purposes, Cronbach alpha was employed resulting in an amount of 0.9047 based on data from questioners and SPSS software outlet. Regarding the outcome of Cronbach alpha, the questioner has necessary reliability and or consistency. Also, for analyzing data, mean test and variation analysis of Friedman by SPSS software were used.

\section{Data Analysis}

Information from sampling and data collection indicate that percentage19.8 students attended entrepreneurship courses out of which percentage66 have shown great interest in doing the courses. For the sake of hypothesis testing, two hypotheses of $H_{0}: \mu \leq 3$ (municipal Scientific and Applied University students are in inappropriate status regarding ....) and $H_{1}: \mu>3$ (municipal Scientific and Applied University students are in appropriate status regarding ....); were examined based on mean comparison test. Results (Table 4) show that the value of meaningfulness score observed for "Proactiveness" variable is Sig=0.000 smaller than standard meaningfulness level $(\% 5=\alpha)$. So, the secondary hypothesis $\mathrm{H} 0\left(H_{0}: \mu \leq 3\right)$ was rejected and $\mathrm{H} 1\left(H_{1}: \mu>3\right)$ was approved at confidence level percentage95. Accordingly, it can be concluded that the students of Municipal Scientific and Applied University are at good level regarding "proactiveness". Data analysis results for other variables are represented in Table 4.

Table 4: analysis of collected data by SPSS Software

\begin{tabular}{lclc}
\hline Variable & Standard meaningfulness level & $\begin{array}{l}\text { Observed } \\
\text { score }\end{array}$ & meaningfulness \\
\hline Proactiveness & 0.05 & 0.000 \\
Innovation & & 0.015 \\
Autonomy & & 0.010 \\
Risk-taking & & 0.000 \\
Competitive aggressiveness & & 0.010 \\
Entrepreneurial attitude & & 0.000 \\
\hline
\end{tabular}

As seen in the Table, the value of meaningfulness score for each variable is smaller than the standard. Therefore, it can be said that all research hypotheses are approved at \%95-confidence level, namely, the students are at good level regarding the variables of entrepreneurship attitude: proactiveness, innovation, autonomy, competitive aggressiveness and risk-taking. In addition, it can be concluded that the students of Municipal Scientific and Applied University are at good level regarding "entrepreneurial attitude ". Friedman variation analysis was employed for ranking the students based on entrepreneurship attitude factors. According to the outcome, observed score value was for the consistency ranking of entrepreneurship attitude (Sig=0.000) and smaller than meaningfulness level $(\alpha=\% 5)$. Therefore, it can be said that at confidence level of \%95, respective entrepreneurship attitude factors do not have equal ranks. Mean rank of each factor is represented in Table 5. As observed, highest mean score is related to proactiveness and the lowest innovation. On the other hand, results from Fridman's analysis test regarding respective variables ground factors indicate that their scores do not go together. Mean factors scores of each is represented in Table 6.

Table 5: mean factors score regarding entrepreneurial attitude

\begin{tabular}{ll}
\hline Variable & Mean score \\
\hline Proactiveness & 3.52 \\
Innovation & 2.36 \\
Autonomy & 3.36 \\
Risk-taking & 2.96 \\
Competitive aggressiveness & 2.80 \\
\hline
\end{tabular}


Table 6: Mean ground factors score regarding entrepreneurial attitude variables

mean ground factors score regarding Proactiveness variable

Planning for taking future job opportunities

The extent of searching for new chances in field of study

The extent of attempt to enhance educational competencies

1.84

2.15

mean ground factors score regarding innovation variable

Mean invention tendency

1.66

2.17

2.17

Zeal for achieving business competency

mean ground factors score regarding autonomy variable

Personal tendency of present new ideas in field of study

Conscious and voluntary cooperation tendency in a creative environment

2.69 perspective

Tendency of use new ideas in workplace from a personal perspective

mean ground factors score regarding risk-taking variable

The extent of taking progressive chances

The extent of risk-taking comparing to others

Extent of belief and tendency of use progressive chances

mean ground factors score regarding competitive aggressiveness variable

Tendency of competing the others

Tendency of overtaking rivals based on competency

Tendency of be in highly competitive environments

\section{Conclusion and Suggestions}

Results show that entrepreneurs play a significant role in development and growth of the societies. To exploit the role, firstly, it is required to encourage the spirit and activity of entrepreneurship using principle policies. Secondly, using necessary policies, the entrepreneurs are to be supported and employed by economic units and in particular small units as entrepreneurship growth context (Chen and Lai, 2010). Developing and expanding entrepreneur's abilities result in entrepreneurship culture. It is a significant factor in employment. Since the graduated employment is a major issue in higher education department, so it seems that removing the unemployment problem of university students owes to developing and expanding entrepreneurship capabilities of individuals itself requiring the very detection of entrepreneurship attitude. Therefore, the study was aimed at examining entrepreneurship attitude of Municipal Scientific and Applied University. Accordingly, after basic studies and distributing questioners among respondents, data was analyzed and each entrepreneurship attitude aspect was examined. Results show that Municipal Scientific and Applied University are at good level regarding "entrepreneurial attitude " (at both main and secondary components), also considering that great percent of the students were interested in attending entrepreneurship courses, it is possible to realize their potential entrepreneurial tendency and purposefully lead them to launching businesses.

Results demonstrate that most students have great tendency of planning, detecting and exploiting employment chances and competencies regarding their field of study and in general, they are at good status at "proactiveness" component. Therefore, providing training and promotional courses considering the recognition of new ideas and opportunities at each field, administering employment planning training courses to make optimum use of educational course time and content as well as inspiring the students to enhance job competencies and launching knowledge-based businesses are useful. Individuals with a need for progression have great tendency of planning, goal setting and gathering information and learning. In other words, the need for progression leads to innovating new ideas. Such a motivation will increase the possibility of persisting on purpose-oriented activities in a long run, so that failures and obstacles cannot stop him (Fazio, 1990). Hal et al study also shows that the higher the need for progression, the further the business plans in three coming years. Henderson and Robertson (2000) also believe that it is possible to stimulate progression by training and develop entrepreneurship, because the need is not innate and can be acquired. Therefore, if we can stimulate the motivation by training, the possibility of discovering entrepreneurial chances will also increase. Another result of the study shows that Municipal Scientific and Applied University students show great interest in doing conscious and voluntary works in open and not controlled environment as well as taking responsibilities and are at good status at autonomy attitude. So, reinforcing the spirit of autonomy and belief in internal control on personal destiny among students 
are suggested, and also it is proposed that required actions being taken by providing optimism culture training courses regarding individuals autonomy in field of study and educational carrier and beside creating supportive atmosphere and using students ideas in academic macro and micro decision making as well as assigning some university projects and activities to the students, the chance is provided for them to represent their own personal opinions and any type of judgment can be avoided.

Because individuals interested in taking new and significant economic actions hate different obligations and the obligations prevent from innovative designs development. They face challenges when encountering power sources. Many of them mentioned their self-employment because of autonomy (Mentoor and Friedrich, 2007). On the other hand, highly efficient individuals comparing to the others have greater tendency toward autonomy and self-organization. They emphasize on controlling their own lives and personal outcomes. An attitude of autonomy, self-employment and self-control is the commonest motivation among self-employed individuals to establish a company (Florin et al., 2007). Another result of the study shows that Municipal Scientific and Applied University students are at good status regarding creativity and innovation. Indeed, many students are interested in discovering and creating novice sources. So, providing straining courses for discovering ideas and other effective courses, setting proper scene for students' individual innovation and creativity to emerge including the provision of instructional facilities, laboratory and workshop, as well as setting cultural scene regarding positive insight into creativity and innovation in the students can be considerably effective in leading the students to innovation and doing entrepreneurial activities. Because some research results demonstrate that selected entrepreneurs choose new jobs not only for economic purposes but mainly also for innovation and creativity existing in them (Kundu and Rani, 2008).

The individual with greater need for innovation is more prepared for change. The need makes the entrepreneur always worried about creating new products, processes and markets (Michael and Shanan, 2008). It is mostly said that entrepreneurs are better risk-takers comparing to ordinary people. In addition, they will discover better and more entrepreneurial chances. Taking risk is an important issue in entrepreneurship since in technical dangers like selling new product; there is always the probability of uncertain profit for entrepreneur (Naffziger et al., 1994). Osborn expresses that despite general belief, entrepreneurs usually take risks that are not at high risk levels. They fit the risk level with their own capabilities. If the individual is not able to adapt, the probability of failure in new deals will be increased (Mentoor and Friedrich, 2007). As a result, instructional and promotion plans regarding detecting vocational chances and setting the scene for risk-taking culture to emerge, providing direct responsibilities in stressful environment and ambiguous academic subjects, collaborative economic investment in students innovative ideas and plans as well as encouraging them accordingly will make great contribution to the students. Because results show that Municipal Scientific and Applied University students are at good status in risk-taking and have great interest in taking probable risks of entrepreneurial activities. Another result indicate that Municipal Scientific and Applied University students are at good status in competitive aggressiveness and show great interest in working in highly competitive and highly standard environments. So to enhance competitive aggressiveness tendency and attitude among university students it is suggested that training courses are administered regarding setting objectives, providence, and competitiveness as vital factors in dynamic changing world and providing competitive atmosphere among the students by promotion plans like entrepreneurial festival and exhibitions at university.

Because entrepreneurs are highly motivated and have great interest in doing in competitive conditions and they want to be the best at everything (Michael and Shanan, 2008). Covin and Slevin (2002) also believe that progression motivation is defined based on the individual self-stimulated thought, frequency SOF competing with high indices and or doing better comparing to the past. Entrepreneurs are hardworking individuals avoiding too easy tasks and preferring to try for superior affairs, however at the same time they choose available goals and searching for feedback from their own deeds. Generally, results show that each of secondary components of entrepreneurial attitude: proactiveness, autonomy, risk-taking, competitive aggressiveness, innovation; are at high priorities for these university students. Nevertheless, presence of appropriate attitude of entrepreneurship among the students of the study, it was approved that appropriate scene for entrepreneurship process emergence exists in university and to complete the process, it is required to move toward enhancing and developing entrepreneurship knowledge and skill in the students and providing proper opportunities for realization of entrepreneurship activities potential at university. Therefore, it is necessary for reinforcement scene to be provided for respective attitude (respectively, innovation, competitive aggressiveness, risk-taking, 
autonomy, and proactiveness) in the students and then by administering some purposeful plans, the action is taken toward enhancing students' knowledge and skill at each of the above attitudes. In addition, finally, proper backgrounds are provided in universities for the emergence of entrepreneurial activities. Accordingly, findings regarding business training and the effect of the students' perception of entrepreneurship studies show that respective instructional plans can increasingly change entrepreneurial attitudes of the participants (Kundu and Rani, 2008).

On the other hand, entrepreneurship skills training affects the individuals' perception of work market and their job self-image (Mentoor and Friedrich, 2007). Schwarz et al (2009) believe that knowledge development affects attitude and attitude affects intent and it affects behavior, so development of entrepreneurship trainings affects individuals' attitude and finally their intent and behavior. Results from another study regarding the examination of emergence and training of entrepreneurship in individuals and by five main entrepreneurship factors: innovation, competitive aggressiveness, risk-taking, autonomy, and proactiveness; demonstrate that educational system must very active in planning for the emergence and nurturing of innovation and creativity so that the attempts set the scene for entrepreneurship development (Autio et al., 2001). In the end, based on the result of this study, conducting studies on the issues like examination and prioritizing students' entrepreneurship needs; the relationship between individuals psychological qualities and entrepreneurship attitude among students; relationship between entrepreneurship attitude and launching students businesses; factors affecting the enhancement of the students' entrepreneurship tendency, all seem necessary for further researches.

\section{References}

Autio, E., Keeley, R., Klofsten, M., Parker, G. \& Hay, M. (2001). Entrepreneurial Intent among Students in Scandinavia and in the USA. Enterprise and Innovation Management Studies, 2(2), 145-160.

Chen, Y. F. \& Lai, M. C. (2010). Factors influencing the entrepreneurial attitude of Taiwanese tertiary-level business students. Social Behavior and Personality, 38(1), 1-12.

Covin, J. G. \& Slevin, D. P. (2002). The entrepreneurial imperatives of strategic leadership. In M.A. Hitt, R.D. Ireland, S.M. Camp, \& D.L. Sexton (Eds.). Strategic entrepreneurship: Creating a new mindset (309-327). Oxford: Blackwell.

Erich, J. S., Malgorzata, A., Wdowiak, D. A., Almer, J. \& Robert, J. (2009). Breitenecker the effects of attitudes and perceived environment conditions on students 'entrepreneurial intent. Education Training, 51(4), 272-291.

Fazio, R. H. (1990). Multiple processes by which attitudes guide behavior: the MODE model as an integrative framework. In M.P. Zanna (Ed.). Advances in experimental social psychology, 23, 75109). San Diego, CA: Academic Press. Frontiers of Entrepreneurship Research, 566-587.

Gibson, L., Gibson, R. \& Zhao, S. (2011). Factors affecting entrepreneurial attitudes of American and Chinese business students, USASBE_2011_Proceedings-Page1021

Gibson, L., Shanan, G., Harris, M. \& Harris, D. (2010). Investigating the Entrepreneurial Attitudes of African Americans: a study of young. Small Business Institute ${ }^{\circledR}$ National Conference Proceedings

Gibson, S. G., Harris, M. \& Harris, D. (2010). Investigating the Entrepreneurial Attitudes of African Americans: a study of young. Small Business Institute ${ }^{\circledR}$ National Conference Proceedings

Harris, M. L. \& Gibson, S. H. (2008). A Comparison of Entrepreneurial Attitudes in the U.S. And China. United States association of small business and entrepreneurship (USASBE) Annual National Conference.

Henderson, R. \& Robertson, M. (2000). Who Wants To Be an Entrepreneur? Young Adult attitudes to entrepreneurship as a career. Career Development International, 5(6), 279-287.

Florin, J., Karri, R. \& Rossiter, N. (2007). Fostering Entrepreneurial Drive in Business Education: An Attitudinal Approach. Journal of Management Education, 31, 17-25.

Kundu, S. \& Rani, S. (2008) .Human resources' entrepreneurial attitude orientation by gender and background: a study of Indian Air Force trainees. Int. J. Management and Enterprise Development, $5(1)$.

Liñán, F., Urbano, D. \& Guerrero, M. (2010). Regional variations in entrepreneurial cognitions: Start-up intentions of university students in Spain. Entrepreneurship and Regional Development.

McCline, R. L., Bhat, S. \& Baj, P. (2000). Opportunity recognition: An exploratory investigation of a component of the entrepreneurial process in the context of the health care industry. Entrepreneurship Theory and Practice, 25, 81-144.

Mentoor, E. \& Friedrich, C. (2007). Is entrepreneurial education at South African universities successful? An empirical example. Industry and Higher Education, 21(3), 231-232. 
Michael, L. H. \& Shanan, G. G. (2008); examining the entrepreneurial attitudes of US business students. Education $p$ Training, 50(7), 568-581

Naffziger, D. W., Hornsby, J. S. \& Kuratko, D. F. (1994). A proposed research model of entrepreneurial motivation. Entrepreneurship Theory and Practice, 17(1), 49 - 55.

Olson, P. D. \& Bosserman, D, A. (1984). Attributes of the entrepreneurial type. Business Horizons, 2, 53-56.

Peterman, N. E. \& Kennedy, J. (2003). Enterprise education: Influencing student's perceptions of entrepreneurship. Entrepreneurship Theory and Practice, 28, 129-144.

Ramsdal, G. H. (2008). Differential relations between two dimensions of self-esteem and the Big Five? Scandinavian Journal of Psychology, 49, 333-338.

Robinson, P. B., Stimpson, D. V., Huefner, J. C. \& Hunt, H. K. (1991). An attitude approach to the prediction of entrepreneurship. Entrepreneurship Theory and Practice. Summer, 13-31.

Rosenberg, M. J. \& Hovland, C. I. (1960). Cognitive, affective, and behavioral components of attitudes. In M. J. Rosenberg, C. I. Hovland, W. J. McGuire, R. P. Abelson, \& J. W. Brehm (Eds.), Attitude organization and change: An analysis of consistency among attitude components. New Haven, CT: Yale University.

Schwarz, E. J., Wdowiak, M. A., Almer-Jarz, D. A. \& Breitenecker, R. J. (2009). The effects of attitudes and perceived environment conditions on students' entrepreneurial intent. Education + Training, 51(4).

Shariff, M. \& Saud, M. B. (2009.) An Attitude Approach to the Prediction of Entrepreneurship on Students at Institution of Higher Learning in Malaysia. International Journal of Business and Management, $4(4)$.

Stormer, F., Kline, T. \& Goldenberg, S. (1999). Measuring entrepreneurship with the General Enterprising Tendency (GET) test: criterion-related validity and reliability. Human Systems Management, 18(1), 47-52.

Vecchio, R. P. (2003). Entrepreneurship and leadership: Some common trends and threads. Human Resource Management Review, 13, 303-327. 